\title{
DESAIN FORMULASI DAN IMPLEMENTASI BISNIS STRATEGIK DENGAN PENDEKATAN BUSINESS MODEL CANVAS (BMC) TERINTEGRASI KERANGKA INTEGRATED PERFORMANCE MANAGEMENT SYSTEM (IPMS) PADA KOPERASI ASPERINDO
}

\author{
Ali Maddinsyah ${ }^{1}$, Dayat Hidayat ${ }^{2}$, Juhaeri3, Denies Susanto ${ }^{4}$, Denok Sunarsi ${ }^{5}$ \\ ${ }^{1,2,3.4}$ Program Pasca Sarjana Magister Manajemen Universitas Pamulang \\ ${ }^{5}$ Program Studi Manajemen, Universitas Pamulang \\ Coresponden Author : alimaddinsyah@unpam.ac.id
}

\begin{abstract}
ABSTRAK
Tujuan dari penelitian untuk menciptakan, merancang dan membuat desain formulasi bisnis strategik dengan menggunakan pendekatan elemen Business Model Canvas (BMC) dan kerangka Integrated Performance Management System (IPMS) sehingga dapat di implementasikan secara tepat pada Koperasi Asperindo. Metode yang digunakan yaitu teknik pengumpulan dilakukan dengan teknik trianggulasi (gabungan), analisis data bersifat induktif/kualitatif. Hasil analisis redesain BMC Koperasi Asperindo didapat 5 komponen yang harus dioptimalisasi diantaranya : Value Propotions. Customer Relations Channels, Key Resource dan Key Partners. Setelah itu mengintegrasikan BMC dengan perancangan kinerja Koperasi Asperindo dengan metode IPMS Framework. Sistem manajemen kinerja dibuat agar sesuai dengan visi, misi dan strategi koperasi. Karena itu, Analisis SWOT dan BMC serta peta strategi digunakan untuk mendapatkan kinerja variabel yang sesuai untuk keberhasilan usaha Koperasi Asperindo. hasil perancangan pengukuran kinerja koperasi dihasilkan 31 sasaran strategis (KPI Koperasi Asperindo). Hasil tersebut merupakan terjemahan dari 9 elemen Building BMC redesain koperasi. Dalam membuat skema penerapan IPMS terdapat lima langkah utama, yaitu: mengembangkan strategi, merencanakan strategi, menyelaraskan organisasi, implementasi, \& monitoring dan pembelajaran.
\end{abstract}

Kata Kunci : Koperasi, Logistik, SWOT, QSPM, BMC, IPMS, AHP, KPI, Peta Strategi

\begin{abstract}
The purpose of this research is to create, design and design strategic business formulations using the Business Model Canvas (BMC) element approach and the Integrated Performance Management System (IPMS) framework so that it can be properly implemented in the Asperindo Cooperative. The method used is the collection technique carried out by triangulation techniques (combined), the data analysis is inductive / qualitative. The results of the analysis of BMC Koperasi Asperindo's redesign show that there are 5 components that must be optimized, including: Value Propotions. Customer Relations Channels, Key Resources and Key Partners. After that, integrate BMC with the performance design of the Asperindo Cooperative with the IPMS Framework method. The performance management system is designed to match the vision, mission and strategy of the cooperative. Therefore, SWOT and BMC analysis and strategy maps are used to obtain the appropriate variable performance for the success of the Asperindo Cooperative business. The results of the cooperative performance measurement design resulted in 31 strategic targets (KPI Koperasi Asperindo). The result is a translation of the 9 elements of the Building BMC cooperative redesign. In making a scheme for implementing the IPMS, there are five main steps, namely: developing a strategy, planning a strategy, harmonizing the organization, implementing, and monitoring and learning.
\end{abstract}

Keywords: Cooperative, Logistics, SWOT, QSPM, BMC, IPMS, AHP, KPI, Strategy Map

\section{PENDAHULUAN}


Seiring pertumbuhan ekonomi dan perkembangan teknologi yang begitu pesat membuat beberapa badan usaha harus berbenah diri untuk menghadapi tantangan perkembangan tersebut. Menurut undang-undang No. 25 Tahun 1992 tentang Perkoperasian. Dalam undang-undang ini menegaskan bahwa pembinaan koperasi, pengesahan perubahan anggaran dasar dan pemberian status badan hukum koperasi merupakan wewenang serta tanggung jawab pemerintah. Wewenang tersebut dapat dilimpahkan pada menteri yang membidangi koperasi. Pertumbuhan keragaan koperasi di Indonesia memang cukup signifikan, dari tahun ke tahun pertumbuhan jumlah koperasi mencapai rata-rata sebesar $5 \%$. Menurut sumber yang di dapat dari Badan Pusat Statistik (BPS), pada tahun 2006 tercatat sebanyak 98.944 koperasi aktif beropers. Selama satu decade,10 tahun lamanya pertumbuhan koperasi di Indonesia meningkat sebesar $66,75 \%$, tepatnya pada tahun 2016 tercatat sebanyak 148.220 koperasi aktif beroperasi di seluruh Indonesia. [1]

Sebuah organisasi dari asosiasi perusahaan jasa pengirman ekspres, pos dan logistik Indonesia atau yang di kenal sebagai ASPERINDO kini tengah membangun kembali koperasinya. Digagas oleh 25 pengurus Asperindo yang membentuk Rapat Anggota Koperasi akhirnya terbentuklah KOPERAS. Berangkat dari fenomena tersebut, Koperasi Asperindo sudah jelas harus memiliki strategi dan model bisnis yang tepat untuk mengelola lembaga ini. Salah satu pendekatan yang dapat digunakan untuk memotret model bisnis Koperasi Asperindo dan kemudian mengembangkan bisnisnya yaitu dengan metode Business Model Canvas (BMC). [2]. [3]

Setelah perencanaan model bisnis dan strategi dirumuskan dengan melalui pendekatan business model canvas, selanjutnya perumusan strategi fungsional dan penentuan ukuran keberhasilan koperasi dilakukan dengan mengukur kinerja koperasi melalui integerasi dari metode Integrated Performance Management System (IPMS) Framework [3], keunggulan IPMS dibandingkan BSC dan Performance Prism, yaitu konsep lebih sederhana dan mudah dimengerti karena hanya menggunakan tiga perspektif saja, yaitu keluaran organisasi, proses internal, dan kemampuan sumber daya. [4].[5]

Penulis memandang bahwa konsep-konsep yang telah dipaparkan di atas harus terdesain, terformulasi dan terintegrasi dengan baik dan tepat, karena fenomena yang terjadi saat ini merupakan waktu yang tepat untuk membuktikan kinerja terbaik koperasi sehingga tercapailah manfaat hasil penelitian yang optimal bagi lembaga tersebut. Agar dari hasil penelitian dapat menghasilkan formulasi model bisnis, strategi bisnis dan perancangan pengukuran kinerja yang tepat sehingga dapat diimplementasikan dengan baik di lembaga koperasi.[5]

\section{LANDASAN TEORI}

\section{A. Koperasi}

Dilihat dari segi bahasa, dari akar katanya koperasi berasal dari kata latin yaitu Cum yang berarti dengan, dan Aperari yang berarti bekerja. Dari dua kata ini, dalam bahasa Inggris dikenal istilah Co dan Operation artinya bekerja dan berusaha. Jadi Cooperation adalah bekerja bersama-sama atau usaha bersama-sama untuk kepentingan bersama, yang dalam bahasa Belanda disebut juga dengan istilah Cooperatieve Vereneging yang berarti bekerja bersama-sama dengan orang lain untuk 
mencapai suatu tujuan tertentu. Sedangkan Mohammad Hatta yang notabene merupakan Bapak Koperasi Indonesia mendefinisikan Koperasi adalah "usaha bersama untuk memperbaiki nasib penghidupan ekonomi berdasarkan tolong menolong".[7].[8].[9]

\section{B. Business Model Canvas (BMC)}

Business Model Canvas (BMC) merupakan model bisnis yang dituangkan secara gambar visual dalam kertas kanvas. Panggung bagian depan (front stage) terdiri atas 5 (lima) panggung yang lebih kecil. Panggung-panggung tersebut ditempati oleh customer segments, value propositions, Channels, Customer Reletionship, Revenue streams. [10]. menyatakan bahwa model bisnis dapat dijelaskan dengan sangat baik melalui sembilan blok bangunan dasar yang memperlihatkan cara berpikir tentang bagaimana perusahaan menghasilkan uang. Kesembilan blok tersebut mencakup 4 bidang utama dalam suatu bisnis, yaitu pelanggan, penawaran, infrastruktur, dan kelangsungan financial. Untuk lebih memudahkan memahaminya[11], perhatikan berikut ini:

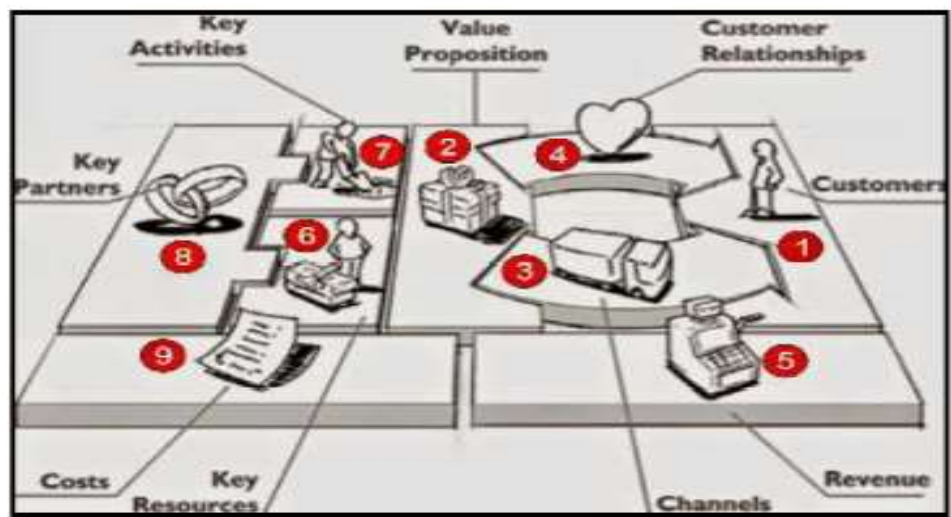

Gambar 1 Business Model Canvas Dalam Bentuk Panggung

(Sumber: Business Model Canvas Penerapan di Indonesia, Tim PPM Manajemen, 2012)

\section{Integrated Performance Management Systems (IPMS)}

Konsep Integrated Performance Management Systems penyempurnaan dari konsep BSC dan Performance Prism karena menggabungkan kesederhanaan disain BSC dengan memadukan perhatian Performance Prism pada stakeholder serta diharapkan dapat diterapkan terutama bagi perusahaan di Indonesia. [12]

\section{METODE PENELITIAN}

Penelitian ini bertujuan untuk mendesain, memformulasikan dan mengimpelementasikan bisnis strategik koperasi dengan integrasi pengukuran kinerja dengan pendekatan Business Model Canvas (BMC) dan Integrated Performance Management System (IPMS Framework). Analisis data disusun dengan langkahlangkah sistematik sebagai kerangka pemecahan masalah bagi penelitian agar sesuai dengan tujuan penelitian[13].[14].15]. Langkah-langkah dalam analisis dipaparkan pada Gambar 2

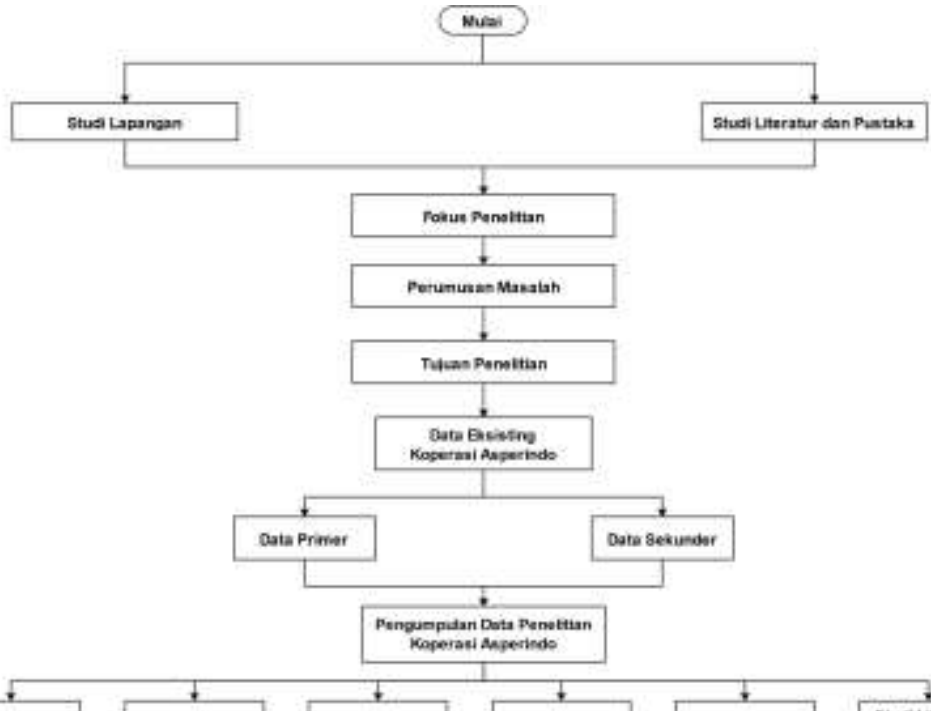


Gambar 2Flow Chart Langkah-Langkah Analisis Data (Sumber: Data Olahan)

\section{Hasil Penelitian dan Pembahasan}

\section{A. BMC Koperasi Asperindo Current}

Berdasarkan hasil analisis mengenai elemen-elemen BMC, maka pemetaan Business Model Canvas (BMC) Koperasi Asperindo[15], seperti pada Gambar 3 berikut:

Business Model Canvas - Koperasi Asperindo (Current)

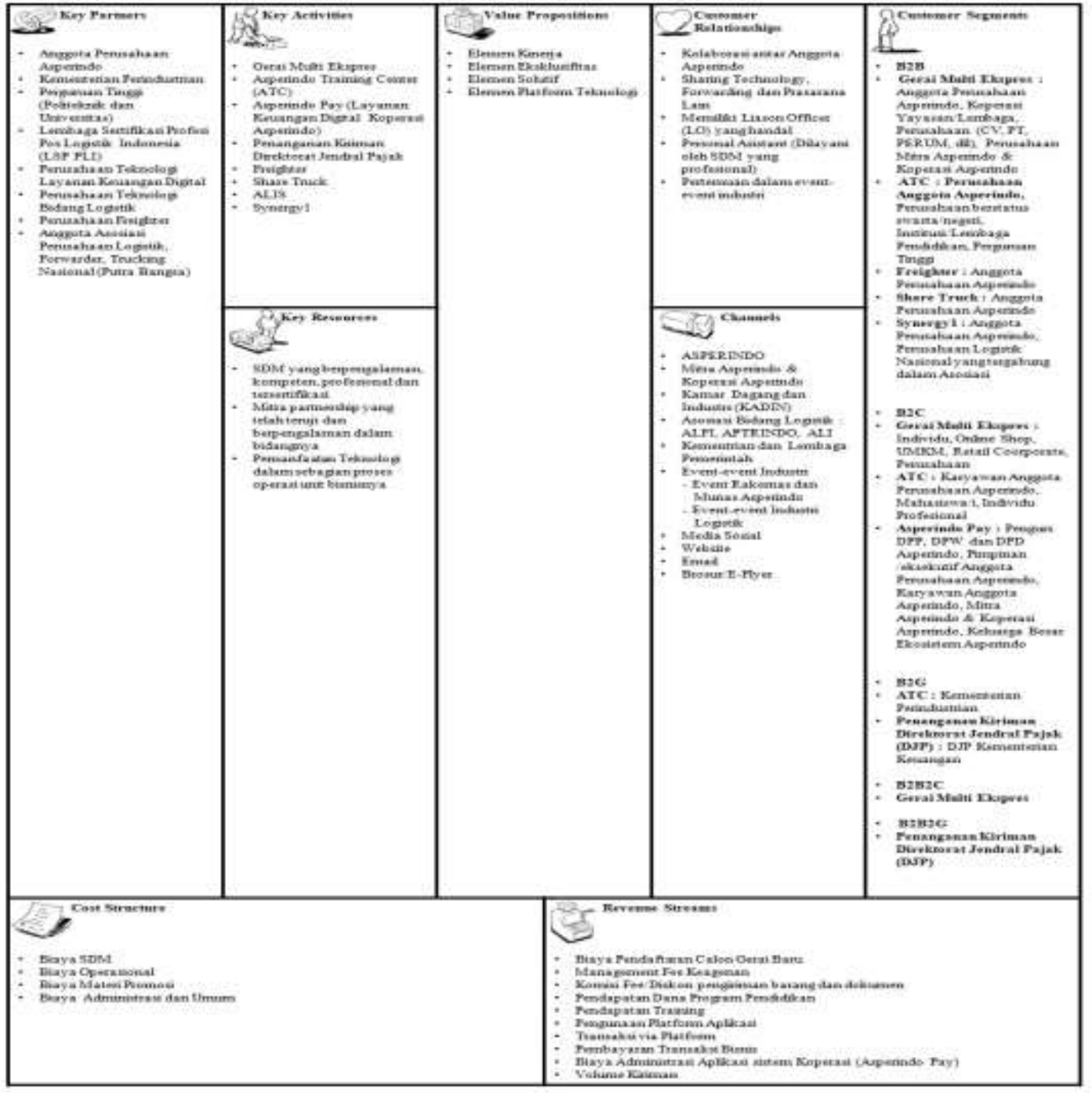




\section{Gambar 3 BMC Koperasi Asperindo Current}

(Sumber: Data Olahan)

\section{B. Analisis IFAS dan EFAS Koperasi Asperindo}

Dari hasil perhitungan matriks Internal Factor Analysis (IFAS) yang diperoleh melalui penyebaran kuesioner, dimana dari hasil skor bobot untuk kekuatan (strength) diperoleh nilai sebesar 2,58. Sedangkan total skor kelemahan sebesar 0,53 ; hal ini menunjukkan bahwa skor kekuatan yang lebih besar dari skor kelemahan. Sehingga dari hasil skor tersebut di atas dapat disimpulkan bahwa berarti Koperasi Asperindo sudah mampu mengatasi kelemahan yang dihadapi selama ini. matriks Eksternal Faktor Analysis (EFAS) pada Koperasi Asperindo dengan nilai skor peluang sebesar 2,44; sedangkan skor ancaman diperoleh sebesar 0,61.

\section{Matriks Space dan Matriks IE}

Dari penentuan formulasi strategi dengan menggunakan matriks space terlihat bahwa nilai SW memiliki nilai selisih positif yakni sebesar 2,05; sedangkan OT positif sebesar 1,83; sehingga Koperasi Asperindo berada dalam posisi kuadran 1 yakni mendukung strategi agresif. Menurut Rangkuti (2013:20) menyatakan bahwa kuadran 1 merupakan situasi yang sangat menguntungkan karena perusahaan tersebut memiliki peluang dan kekuatan sehingga dapat memanfaatkan peluang yada ada. Strategi yang harus ditetapkan dalam kuadran ini adalah mendukung kebijakan pertumbuhan yang agresif (Growth Oriented Strategy). Kemudian langkah selanjutnya adalah memindahkan skor nilai ke dalam matrik IE. Nilai terbobot total untuk IFAS pada masa sekarang adalah 3,10. Sedangkan nilai terbobot total untuk EFAS adalah 3,05. Dari Tabel Matriks IE Koperasi Asperindo yakni diketahui Koperasi Asperindo berada dalam Sel 1, dimana posisi tersebut koperasi berada dalam strategi pertumbuhan, alasannya karena skor IFAS dan skor EFAS memiliki nilai positif, selain itu dalam tabel tersebut di atas terlihat bahwa skor IFAS dan Skor EFAS sudah memiliki nilai skor tinggi.

\section{TOWS Matriks}

Berdasarkan Matriks TOWS di atas, terlihat ada 8 (delapan) alternatif strategi, sebagai berikut:

1. Strategi SO

Strategi SO ada 2 (dua), yaitu:

a. Mengembangkan dan meningkatkan potensi utilitas bisnis koperasi dan pelayanan jasa yang prima dalam memenuhi permintaan pasar dan merespon pertumbuhan serta perubahan yang signifikan dalam bidang sumber daya, infrastruktur, kebijakan, lingkungan, teknologi dan bisnis

2. Mengoptimalkan kolaborasi antar perusahaan dan sinergi asosiasi demi menciptakan sustainable bisnis yang positif dan mendorong pembangunan SDM Logistik yang kompeten agar proporsi nilai bisnis tercapai dengan baik Strategi WO

Strategi WO yang dihasilkan ada 2 (dua), sebagai berikut:

a. Meningkatkan promosi unit bisnis Koperasi secara masif dan terstruktur dengan saluran yang telah teridentifikasi secara tepat melalui jaringan bebabasis teknologi digital yang pemanfaatannya juga berdampak pada pengembangan jaringan, distribusi dan otomasi kepada pelanggan

b. Mengoptimalkan SDM yang berkualitas dan berbasis pada kompetensi untuk dapat mengembangkan segala aspek yang diperlukan oleh Koperasi Asperindo

3. Strategi ST 
Strategi ST yang dihasilkan ada 2 (dua), sebagai berikut:

a. Meningkatkan kualitas jasa/produk Koperasi Asperindo dengan mengoptimalkan value chain dan value added kepada pelanggan untuk penguasaan pasar dan sebagai usaha mempertahankan serta meningkatkan loyalitas pelanggan

b. Secara berkelanjutan melakukan inovasi bisnis koperasi berbasis teknologi dan berdasarkan kebutuhan pasar serta melakukan improvement secara berkesinambung kinerja pelayanan koperasi sehingga tingkat kepuasaan pelanggan terpenuhi

4. Strategi WT

Strategi WT yang dihasilkan ada 2 (dua), yaitu:

a. Meningkatkan loyalitas dan kepuasan pelanggan melalui manajemen pelayanan yang paripurna agar tidak beralih ke merek pesaing atau bidang bisnis lainnya

b. Meningkatkan fasilitas pendukung operasional dalam mendukung pengembangan dan keberlanjutan bisnis Koperasi Asperindo agar tidak tergerus oleh pesaing atau jasa substitusi lainnya

\section{Analisis Formulasi QSPM}

Dari hasil analisis Quantitative Strategies Planning Matrix (QSPM) dalam penentuan bisnis strategik pada Koperasi Asperindo maka pilihan strategi yang diusulkan untuk digunakan oleh Koperasi Asperindo adalah strategi pertumbuhan (agresif). Dari hasil QSPM di dapat bahwa strategi paling optimal dan prioritas yaitu dapat di terapkan yaitu strategi penetrasi pasar dengan nilai TAS sebesar 6,08 selanjutnya strategi pengembangan pasar dengan nilai TAS sebesar 5,69 dan terakhir strategi pengembangan produk dengan nilai TAS sebesar 5,59. Dari hasil nilai TAS yang di dapat dari analisis QSPM dapat disimpulkan strategi penetrasi pasar dapat dipilih dan menjadi acuan strategi prioritas dan teroptimal. Ketiga strategi tersebut merupakan strategi pilihan yang diharapkan dapat diimplementasikan untuk menjadi desain formulasi bisnis strategi Koperasi Asperindo.

\section{Redesain BMC Koperasi Asperindo}

Setelah menetapkan pilihan strategis, untuk memperkuat ketangguhan strategi tersebut dibutuhkan dukungan bisnis model. Perpaduan antara elemen elemen dalam Business Model Canvas (BMC) dengan strategi bisnis yang telah diformulasikan bermanfaat untuk memudahkan implementasi strategi bisnis yang direkomendasikan. Perubahan komponen-komponen tersebut juga merupakan hasil kajian peneliti dan hasil diskusi dengan beberapa personil kunci dan hasil diskusi dengan Forum Group Discussion yang telah aktif memberikan saran dan pandangan-pandangan.

\section{Integrasi BMC dengan Metode IPMS}

Keunggulan IPMS dibandingkan BSC dan Performance Prism, yaitu konsep lebih sederhana dan mudah dimengerti karena hanya menggunakan tiga perspektif saja, yaitu keluaran organisasi, proses internal, dan kemampuan sumber daya; kerangka kerja IPMS sangat lengkap dan mudah dimengerti; penjelasan mengenai proses mendisain diberikan mulai dari fondasi SMK, metode-metode analisis kondisi lingkungan usaha, cara menghubungkan strategi dengan SMK, kerangka kerja pengukuran kinerja, langkah-langkah implementasi SMK, dan proses pemuktahiran SMK; kerangka kinerja IPMS dapat diterapkan ke dalam industry apa saja, yang menghasilkan produk serta jasa dan menjelaskan prosedur benchmarking dengan sangat jelas.

\section{Perancangan IPMS}

\section{a. Tahap 0: Fondasi}

Ada empat prinsip dan lima kaidah yang harus diperhatikan dalam merancang

SMK yang baik. Empat Prinsip tersebut yaitu : Kemitraan menyeluruh antara manajemen, karyawan, konsumen, dan pemasok, Pemberdayaan seluruh 
karyawan, Perbaikan kinerja yang terintegrasi dan Tim yang mandiri. Lima Kaidah tersebut yaitu : KISS (Keep it Stupid Simple), Berorientasi jangka panjang, Beri feedback sesegera mungkin, Fokus pada perbaikan berkelanjutan, Gunakan pendekatan kuantitatif (Wibisono, 2006:26)

\section{2) Tahap 1: Informasi Dasar}

Analisis dilakukan dengan menggunakan konsep Busines Model Canvas dan Analisis SWOT yang telah disajikan pada pembahasan sebelumnya.

3) Tahap Perencanaan

Indikator kinerja IPMS terdiri dari 3 perspektif, yaitu keluaran organisasi, proses internal, dan kemampuan sumber daya. Desain dan Proses Perancangan Kinerja IPMS meliputi analisis visi dan misi, strategi perusahaa dan kerangka kerja sistem manajemen kinerja yang mencakup Sasaran strategis, kinerja variabel, $\mathrm{KPI}$.

\section{Pembobotan Sasaran Strategis Variabel Kinerja dengan AHP}

Dari hasil pembobotan variabel kinerja dari tiap perspektif dengan menggunakan AHP di dapat bobot nilai tertinggi dari masing masing perspektif yang menjadi prioritas variabel. Pada perspektif keluaran organisasi di dapat bobot nilai tertinggi pada variabel kinerja Revenue Growth dengan nilai 0,110; Pada perspektif proses internal di dapat bobot nilai tertinggi pada variabel kinerja Tingkat Cross Selling dengan nilai 0,1094; Pada perspektif kemampuan sumber daya di dapat bobot nilai tertinggi pada variabel kinerja kompetensi karyawandengan nilai 0,099.

\section{Keterkaitan Antar Variabel}

Analisis yang dilakukan didasarkan pada hubungan formula pengukuran kinerja dalam perhitungan variabel. Hasil keterkaitan antar variabel dijelaskan dalam Gambar 4 berikut:

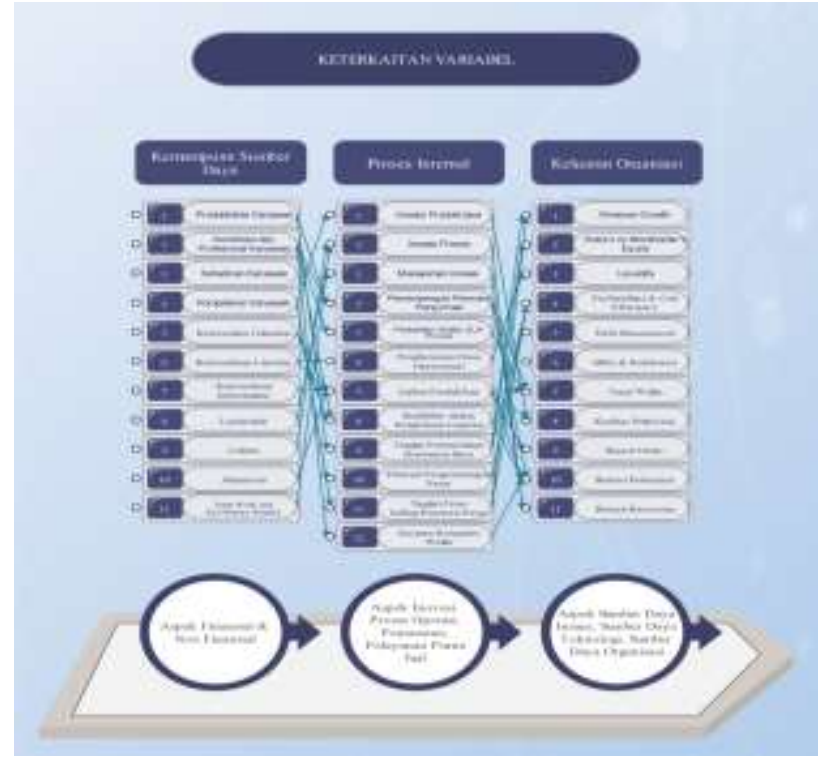

\section{Gambar 4 Keterkaitan Antar Variabel Kinerja \\ (Sumber : Data Olahan)}

\section{Penyusunan Peta Streategi Level Korporat}

Dalam peta strategi atau strategy map yang dirancang menunjukkan hubungan yang komprehensif dan koheren antar setiap sasaran strategis pada ketiga perspektif IPMS Koperasi Asperindo. Puncak keterkaitan hubungan sebab-akibat berada pada peningkatan kinerja finansial, yaitu kesejahteraan para stakeholder guna pertumbuhan dan keberlanjutan usaha koperasi. Setiap sasaran strategis yang telah digambarkan memiliki hubungan sebab akibat yang jelas. Dari setiap tujuan strategis, secara 
langsung maupun tidak langsung akan mengarah pada peningkatan kinerja keuangan perusahaan. berikut merupakan hubungan sebab akibat dari setiap perspektif.

\section{Peta Strategi Koperasi Asperindo}

Peta strategi menyediakan arsitektur untuk mengintegrasikan strategi dan operasi unit yang berbeda tersebar di seluruh perusahaanatau koperasi dalam hal ini. Proses merencanakan strategi dikonversi pernyataan arah strategis ke tujuan spesifik, tindakan, target, inisiatif dan anggaran memandu tindakan dan menyelaraskan koperasi untuk pelaksanaan strategi yang efektif. Semua data untuk peta strategis berasal dari perancangan pengukuran kinerja dengan pendekatan IPMS. Peta strategi menjelaskan proses penciptaan nilai melalui serangkaian hubungan sebab-akibat di antara tujuan (Kaplan \& Norton, 2008: 98). Dalam hal ini penulis menggunakan peta strategi menjadi tiga perspektif IPMS: kemampuan sumber daya, proses internal dan keluaran organisasi.

\section{Skema Penerapan IPMS Koperasi Asperindo,}

Ada lima langkah utama dari skema penerapan IPMS ini, yaitu: mengembangkan strategi, merencanakan strategi, menyelaraskan organisasi, implementasi, \& monitoring dan pembelajaran

\section{Penerapan IPMS}

Berikut ini diagram mekanisme penerapan sistem menejemen kinerja untuk Koperasi Asperindo, seperti dilihat pada Gambar 5 berikut :

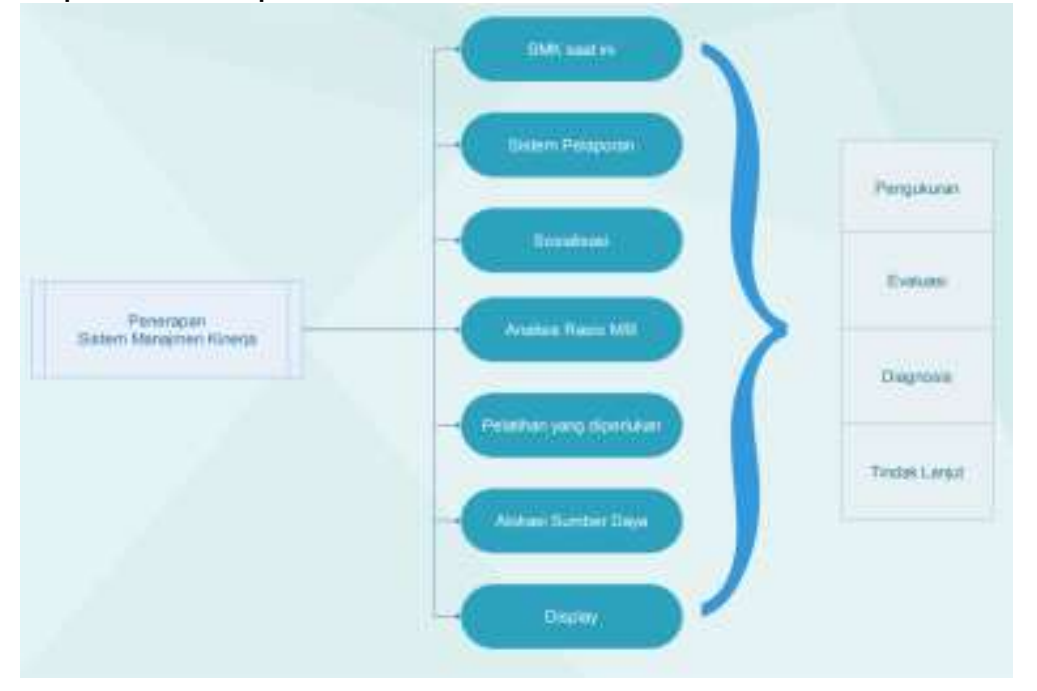

Gambar 5 Mekanisme Penerapan SMK IPMS

(Sumber: Data Olahan di sadur dari buku How to Create a World Class Company, Wibisono 2012)

Penerapan sistem pengukuran kinerja yang mengikuti konsep IPMS mengacu kepada empat tahap, yaitu : pengukuran, evaluasi, diagnosis, dan tindak lanjut. Dalam rencana implementasi, keempat hal tersebut juga harus dilakukan dengan periode waktu yang ditentukan bersama. Secara garis besar implementasi pengukuran dapat dijelaskan sebagai berikut :

1. Penentuan target, dilakukan di akhir tahun setelah evaluasi kinerja tahun berjalan

2. Pengukuran kinerja, dilakukan setiap bulan dan atau sesuai dengan formula pengukuran kinerja yang telah di tetapkan

3. Evaluasi dilakukan setiap kuartal bagi sumber daya internal dan setiap akhir kontrak untuk unit bisnis

4. Diagnosis dilakukan saat evaluasi dengan membandingkan antara target pencapaian kinerja dengan kinerja aktual yang dilakukan sumber daya dan stakeholder. Jika terjadi penyimpangan, dapat segera dilakukan perbaikan. 


\section{Display}

Tampilan sistem pengukuran kinerja harus dibuat semenarik mungkin. Agar informasi kinerja selalu dapat diperbarui dan diinformasikan satu sama lain dengan segera, sehingga perlu dukungan dari perangkat lunak pendukung yang dapat menyajikan komunikasi tampilan yang dapat dilihat oleh seluruh divisi atau bagian yang bersangkutan.

\section{KESIMPULAN DAN SARAN}

\section{A. Kesimpulan} berikut:

Adapun kesimpulan yang terdapat dalam studi penelitian ini adalah sebagai

1. Dalam proses perancangan desain dan implementasi formulasi bisnis strategik Koperasi Asperindo dengan menggunakan pendekatan analisis Business Model Canvas (BMC), analisis STEEPLE \& Five Forces, analisis SWOT dan analisis QSPM, peneliti berhasil merumuskan formulasi strategi bisnis yang sesuai dengan kondisi Koperasi Asperindo, yaitu strategi pertumbuhan (agresif) dengan stratergi prioritas pada penetrasi pasar secara maksimal dengan nilai TAS 6,08 yang didukung strategi inisiatif, sebagai berikut:

a. Meningkatkan potensi utilitas bisnis koperasi dan pelayanan jasa yang prima dalam memenuhi permintaan pasar

b. Meningkatkan promosi unit bisnis Koperasi secara masif dan terstruktur dengan saluran yang telah teridentifikasi secara tepat melalui jaringan bebabasis teknologi digital

c. Meningkatkan kualitas jasa/produk Koperasi Asperindo dengan mengoptimalkan value chain dan value added kepada pelanggan

d. Meningkatkan loyalitas dan kepuasan pelanggan melalui manajemen pelayanan yang paripurna agar tidak beralih ke merek pesaing atau bidang bisnis lainnya

2. Dalam mencapai keberhasilan usaha Koperasi Asperindo dirancanglah pengukuran kinerja untuk mengetahui efektifitas dan efisiensi terkait kinerja koperasi. Perancangan pengukuran kinerja Koperasi Asperindo menghasilkan 3 perspektif IPMS dan 9 aspek IPMS Dari sasaran strategis tersebut didapatkan 31 KPI yang terdiri dari 34 variabel dengan rincian 11 variabel pada perspektif kemampuan sumber daya, 12 variabel pada perspektif proses internal dan 11 variabel pada perspektif keluaran organisasi. Dalam skema penerapan IPMS Koperasi Asperindo terdapat lima langkah utama yaitu : mengembangkan strategi, merencanakan strategi, menyelaraskan organisasi, implementasi, \& monitoring dan pembelajaran, menganalisis penerpan/implementasi IPMS dan membuat display IPMS dengan radar chart.

B. Saran

Adapun saran yang terdapat dalam studi penelitian ini adalah sebagai berikut:

1. Dalam menerapkan strategi dan perancangan sistem manajemen kinerja koperasi disarankan untuk mengikuti pedoman tahap-tahap dalam penelitian ini, agar hasil dari implementasi dapat berjalan dengan optimal dan tepat sasaran sebagai usaha mencapai tujuan koperasi.

2. Usulan yang diajukan oleh penulis dalam penelitian ini hendaknya disesuaikan dengan kemampuan koperasi dalam implementasinya karena tidak secara keseluruhan usulan mampu diimplementasikan mengingat keterbatasan resources yang dimiliki.

3. Desain dan implementasi formulasi ini harus dilakukan secara berkesinambungan walaupun penelitian ini telah selesai, guna tetap terjaganya kualitas pelayanan dan kepuasaan terhadap pelanggan (ultimate end costumer). 
Penelitian ini ditunjukkan kepada peneliti selanjutnya untuk menjadi acuan atau landasan dalam membuat penelitian berikutnya dan diharapkan penelitian selanjutnya mampu mengembangkan penelitian, baik dari segi tempat, perspektif dan metode yang akan dipakai

\section{DAFTAR PUSTAKA}

[1] https://www.bps.go.id/statictable/2014/01/15/1314/jumlah-koperasi-aktifmenurut-provinsi--2006-2016.html

[2] Ikatrinasari, Z. F. 2017. Pengembangan Model Bisnis Koperasi Ritel Kareb Bojonegoro Jawa Timur, Prosiding SNTI dan SATELIT 2017 (pp. F171-177) Jurusan Teknik Industri. Universitas Brawijaya: Malang.

[3] Wibisono, D., 2011. Manajemen Kinerja Korporasi dan Organisasi: Panduan Penyusunan Indikator. INA: Penerbit Erlangga

[4] Maddinsyah, A., Sunarsi, D., Hermawati, R., Pranoto. (2020). Analysis of location selection effect on the user decision that influcence the success of the service business of micro, small and medium enterprise (MSME) in bandung timur region. International Journal of Advanced Science and Technology. Vol. 29 No. 06

[5] Fitrianto, G., dan Tresnadihimad, M. 2016. Performance Management System Design for a Muslim Apparel Company in Indonesia (Case Study PT.

BersamaZatta Jaya), Banking and Management Review Vol 5 No. 1, Mei 2016. Institut Teknologi Bandung: Bandung.

[6] Effendy, A., \& Sunarsi, D. (2020). Persepsi Mahasiswa Terhadap Kemampuan Dalam Mendirikan UMKM Dan Efektivitas Promosi Melalui Online Di Kota Tangerang Selatan. Jurnal IImiah MEA (Manajemen, Ekonomi, \& Akuntansi), 4(3), 702-714. https://doi.org/10.31955/mea.vol4.iss3.pp702-714

[7] Baswir, Revisond. 2003. Ekonomi Kerakyatan Ekonomi Rakyat dan Koperasi Sebagai Sokoguru Perekonomian Nasional. Pusat Studi Ekonomi Kerakyatan UGM, Yogyakarta.

[8] Hatta, Mohammad.1971. Membangun Koperasi dan Koperasi Membangun. Penerbit PT Inti Idayu Press, Jakarta

[9] Wijaya, A., Karel, R., dan Vincent. 2018. Penerapan Model Bisnis Fintech Pada Koperasi Petal, Tesis. Binus University: Jakarta

[10] A. Osterwalder dan Y. Pigneur, Business Model Generation, Amsterdam: Modderman Drukwerk, 2009.

[11] Kaplan, Robert S. dan David P. Norton 2004. The Strategy Map, Harvard Business School Press. Boston: MA

[12] Kaplan, Robert S. dan David P. Norton 1996. Balanced Scorecard: Menetapkan Strategi Menjadi Aksi. Jakarta: Penerbit Erlangga.

[13] Sugiyono. 2011. Metode Penelitian Kuantitatif, Kualitatif dan R\&D. Penerbit: Alfabeta, Bandung

[14] Gracia, H. 2018. Strategi Pengembangan Bisnis Pada Usaha Kemiri Dengan Pendekatan Business Model Canvas (BMC) Di Desa Mattampapole, Kecamatan Mallawa, Kabupaten Maros, Tugas Akhir. Universitas Hasanuddin: Makasar.

[15] Makkulau, Andi. 2017. Analisis Strategi Bisnis Dalam Meningkatkan Market Share Dengan Menggunakan Pendekatan Analisis Business Model Canvas (BMC) dan Swot Analysis Pada PT Semen Tonasa (Studi Kasus Daerah Pemasaran Sulawesi Selatan), Tesis. Universitas Hasanuddin: Makasar. 